\title{
EVALUATION OF TOTAL LYMPHOCYTE COUNT, BODY MASS INDEX, HAEMOGLOBIN AND ALBUMIN LEVELS AS LOW COST SURROGATE MARKERS FOR CD4 COUNTS IN ASSESSING DISEASE PROGRESSION IN HIV/AIDS- A DESCRIPTIVE STUDY
}

\author{
Daranendran Chellappa ${ }^{1}$, Subramanian Vadivel $^{2}$
}

${ }^{1}$ Assistant Professor, Department of Internal Medicine, Government Villupuram Medical College, Tamilnadu. ${ }_{2}^{2}$ Assistant Professor, Department of Internal Medicine, Government Villupuram Medical College, Tamilnadu.

\section{ABSTRACT}

\section{BACKGROUND}

Infection with HIV progresses to AIDS at different rates in different individuals with a spectrum varying from rapid progression to long-term non-progression. Thus, it becomes essential to have tests which accurately assesses the stage of the disease as well as predicting the progression. The single best predictor so far used being the Plasma HIV RNA load and the CD4+ T cell count. Plasma viral load testing with its reliance on sophisticated laboratories and patented PCR kits has also been extremely challenging to scale up in resource limited settings. Hence, the need for evaluation of surrogate markers for identifying disease progression.

The aim of this study is to evaluate the effectiveness of Total Lymphocyte Count, Body Mass Index, Haemoglobin and Albumin levels as low-cost surrogate markers in predicting disease progression in HIV/AIDS.

\section{MATERIALS AND METHODS}

This is a Descriptive Study; 100 patients fulfilling the above-mentioned criteria were included in the study. Their presenting Total Lymphocyte Count, Body Mass Index, Haemoglobin and Albumin levels were correlated with their CD4 counts and to their clinical staging. The feasibility of using these parameters as low cost surrogate markers instead of CD4 count in assessing the progression of the disease was finally evaluated. The statistical method used for analysis was Spearman's Rho rank correlation test. Analysis was done using IBM SPSS statistical software Version 20.0.

\section{RESULTS}

A total of 100 patients were included into the study. Patients in stage I disease had a mean CD4 count of 665 [SD 219.82 ]. There was a significant drop in the mean CD4 count in the stage II disease to 298 [SD 74.54]. There was still further drop in the CD4 count in stages III and IV to 195 [SD 118.03] and 146 [SD 85.09] respectively, proving the well-known fact that fall in CD4 count is a marker of disease progression in HIV. The range of TLC in our study was between 906 and 4256. Patients in the stage I disease had a mean TLC of 3246 [SD 524.98]. There was a significant drop in the mean TLC in the stage II disease to 2053 [SD 362.04 ]. There was still further drop in the TLC in stages III and IV to 1460 [SD 346.85] and 1343 [SD 310.00], respectively. There is strong positive correlation between CD4 count and TLC, HB, BMI and Serum Albumin.

\section{CONCLUSION}

HIV infection is common in third-to-fifth decade of life with higher prevalence in males. TLC together with BMI, HB and Serum Albumin levels are sensitive surrogate markers for CD4 counts in predicting the progression of HIV/AIDS.

\section{KEYWORDS}

HIV, Surrogate Markers, CD4 Count.

HOW TO CITE THIS ARTICLE: Chellappa D, Vadivel S. Evaluation of total lymphocyte count, body mass index, haemoglobin and albumin levels as low cost surrogate markers for CD4 counts in assessing disease progression in HIV/aids- a descriptive study. J. Evolution Med. Dent. Sci. 2017;6(76):5439-5442, DOI: 10.14260/Jemds/2017/1180

\section{BACKGROUND}

Infection with HIV progresses to AIDS at different rates in different individuals with a spectrum varying from rapid progression to long-term non-progression. This variable course of HIV infection complicates the design and interpretation of the therapeutic options along with emotional trauma to the patient. Many clinical and laboratory

Financial or Other, Competing Interest: None.

Submission 21-08-2017, Peer Review 08-09-2017,

Acceptance 15-09-2017, Published 21-09-2017.

Corresponding Author:

Dr. Subramanian Vadivel,

Assistant Professor,

Department of Internal Medicine,

Government Villupuram Medical College,

Tamilnadu.

E-mail: subbusujeeth@gmail.com

DOI: $10.14260 /$ jemds $/ 2017 / 1180$ markers have been used to estimate the progression of the disease like HIV related symptoms, Plasma

HIV RNA load, p24 Antigen assay, depletion of CD4 counts, Total lymphocyte count, Haemoglobin levels, Body Mass Index, serum Albumin levels, neopterin levels, cutaneous anergy, elevated levels of b2 microglobulin, etc.

The single best predictor ${ }^{1}$ so far used being the Plasma HIV RNA load and the CD4+ T cell count. Plasma viral load testing with its reliance on sophisticated laboratories and patented PCR kits has also been extremely challenging to scale up in resource limited settings. Widespread and routine use of CD4 counts and plasma viral load in the management of HIV has not been possible in resource limited settings. In this study, we are evaluating "Total Lymphocyte Count, Haemoglobin level, Body Mass Index and serum Albumin as low cost surrogate markers for disease progression in HIV/AIDS." 


\section{Aim}

To evaluate the effectiveness of Total Lymphocyte Count, Body Mass Index, Haemoglobin and Albumin levels as low cost surrogate markers in predicting disease progression in HIV/AIDS.

\section{Objectives}

1. To study the correlation of Total Lymphocyte Count, Body Mass Index, Haemoglobin and Albumin levels with disease progression in HIV.

2. To find out whether Total Lymphocyte Count, Body Mass Index, Haemoglobin and Albumin levels as low cost surrogate markers in predicting disease progression in HIV/AIDS.

\section{MATERIALS AND METHODS \\ Design of the Study}

This is a Descriptive Study.

\section{Inclusion Criteria}

HIV positive patients attending Medical OPD, ART Clinic and In-Patients from Medical wards in Government Villupuram Medical College, Villupuram.

1. Both newly diagnosed/registered HIV/AIDS patients at Govt. Villupuram Medical College.

2. Patients on/off ATT/ART.

3. Age more than 12 years.

\section{Exclusion Criteria}

1. HIV positive patients with leukaemia, lymphoma, liver failure or renal failure.

2. PLHIV who are on Zidovudine [anaemia induced by AZT].

3. PLHIV who are obese.

\section{Consent}

Informed written consent was obtained; 100 patients fulfilling the above-mentioned criteria were included in the study. Their full clinical profile including age and sex distribution, occupation, marital status including status of spouses and children, high-risk behaviour and co-morbid conditions were analysed. Prevalence of TB and other coinfections in the study population was also analysed. They were staged according to the WHO clinical staging criteria. Their presenting Total Lymphocyte Count, Body Mass Index, Haemoglobin and Albumin levels were correlated with their CD4 counts and to their clinical staging. The feasibility of using these parameters as low cost surrogate markers instead of CD4 count in assessing the progression of the disease was finally evaluated.

\section{Analysis of Data}

By using IBM SPSS statistical software Version 20.0. The nonparametric statistical Spearman's rho rank correlation test was used to determine the relationship between CD4 and other variables.

\section{RESULTS}

A total of 100 patients were included into the study. The range of CD4 count in our study was between 33 and 1270 . Patients in stage I disease had a mean CD4 count of 665 [SD 219.82]. There was a significant drop in the mean CD4 count in the stage II disease to 298 [SD 74.54]. There was still further drop in the CD4 count in stages III and IV to 195 [SD 118.03] and 146 [SD 85.09] respectively, proving the wellknown fact that fall in CD4 count is a marker of disease progression in HIV [Table 1].

The range of TLC in our study was between 906 and 4256 . Patients in the stage I disease had a mean TLC of 3246 [SD 524.98]. There was a significant drop in the mean TLC in the stage II disease to 2053 [SD 362.04]. There was still further drop in the TLC in stages III and IV to 1460 [SD 346.85] and 1343 [SD 310.00] respectively [Table 2]. Correlating CD4 values with TLC, we derive that in our study population 33 patients who had CD 4 counts less than 200 had a mean TLC of 1198 . Those patients who had CD4 counts $350-500$ and $>500$ had a mean TLC of 1895 and 2895, respectively. The scatter diagram shows almost a straight line with minimal scatter [Figure 1]. There is strong positive correlation 0.910 between CD4 count and TLC, which is statistically significant of ' $p$ ' value $<0.0012$.

The range of HB in our study was between $5.2 \mathrm{gm} \%$ and $13.2 \mathrm{gm} \%$. Patients in stage I disease had a mean HB of 10.6 [SD 1.16] gm\%. There was a drop in the mean HB in the stage II disease to 9.6 [SD 0.52] gm\%. There was still further drop in the HB in stages III and IV to 8.1 [SD 1.25] gm\% and 7.1 [SD 1.04] gm\% respectively [Table 3]. Correlating CD4 values with $\mathrm{HB}$, we derive that in our study population 33 patients who had CD4 counts less than 200 had a mean HB of 7.2 gm\%. Those patients who had CD4 counts of $200-350$ and $>350$ had a mean HB of 9.2 gm\% and 10.4 gm\% respectively [Figure 2]. There is a strong positive correlation 0.859 between CD4 count and HB.

The range of BMI in our study was between 17.2 and 24.7. Patients in stage I disease had a mean BMI of 22.6 [SD 0.93]. There was a drop in the mean BMI in the stage II disease to 20.1 [SD 0.61]. There was still further drop in the BMI in stages III and IV to 18.9 [SD 0.94] and 17.9 [SD 0.35] respectively [Table 4]. Correlating CD4 values with BMI, we derive that in our study population 33 patients who had CD4 counts less than 200 had a mean BMI of 18.3. Those patients who had CD4 counts $200-350$ and $>350$ had a mean BMI of 19.6 and 21.8, respectively. There is a strong correlation 0.852 between CD4 count and BMI [Figure 3]. The range of Serum albumin in our study was between 5.4 and $2.6 \mathrm{gm} \%$. Patients in stage I disease had a mean value of 4.4 [SD 0.50] gm $\%$. There was a drop in the mean albumin in stage II disease to 3.8 [SD 0.28] gm\%. There was still further drop in stages III to 3.54 [0.57] gm\% and stage IV 3.26 [SD 0.39] gm\% [Table 5]. Correlating CD4 values with albumin, we derive that in our study population 33 patients who had CD4 counts less than 200 had a mean BMI of $3.7 \mathrm{gm} \%$. Those patients who had CD4 counts of $200-350$ and > 350 had a mean value of 3.9 and $4.4 \mathrm{gm} \%$, respectively. The scatter diagram shows minimal scatter [Figure 4]. There is a strong positive correlation between CD4 count and albumin levels, 0.895 .

\begin{tabular}{|c|c|c|c|c|c|c|c|}
\hline \multicolumn{2}{|c|}{ CD4 } & Count & Mean & Median & Min & Max & $\begin{array}{c}\text { Standard } \\
\text { Deviation }\end{array}$ \\
\hline \multirow{4}{*}{ 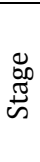 } & I & 16 & 665.00 & 625.50 & 299.00 & 1270.00 & 219.82 \\
\hline & II & 30 & 297.67 & 281.50 & 168.00 & 485.00 & 74.54 \\
\hline & III & 40 & 194.93 & 195.50 & 15.00 & 448.00 & 118.03 \\
\hline & IV & 14 & 146.14 & 120.00 & 33.00 & 305.00 & 85.09 \\
\hline
\end{tabular}




\begin{tabular}{|c|c|c|c|c|c|c|c|}
\hline \multicolumn{2}{|c|}{ TLC } & Count & Mean & Median & Min & Max & $\begin{array}{l}\text { Standard } \\
\text { Deviation }\end{array}$ \\
\hline \multirow{4}{*}{ 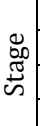 } & I & 16 & 3246.25 & 3121.00 & 2104.00 & 4256.00 & 524.98 \\
\hline & II & 30 & 2052.63 & 1963.00 & 1404.00 & 2752.00 & 362.04 \\
\hline & III & 40 & 1460.35 & 1503.00 & 906.00 & 2018.00 & 346.85 \\
\hline & IV & 14 & 1343.29 & 1284.00 & 958.00 & 1856.00 & 310.00 \\
\hline
\end{tabular}

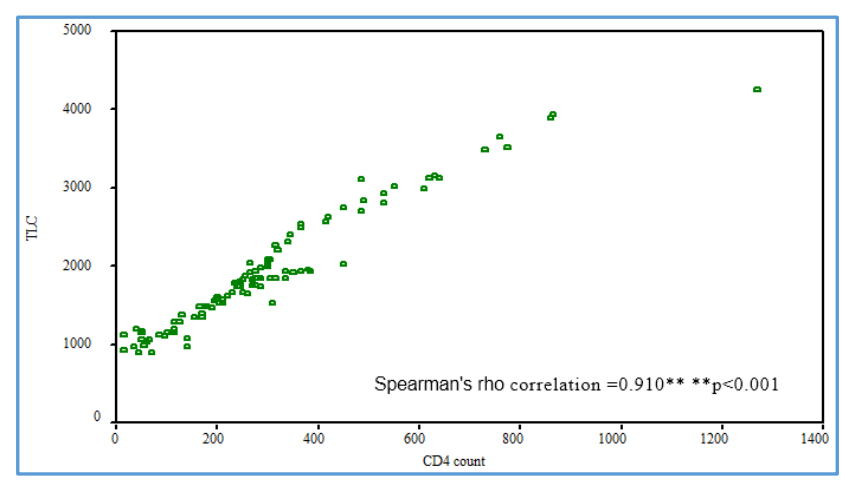

Figure 1. Distribution of TLC in Correlation to CD4 Count

\begin{tabular}{|c|c|c|c|c|c|c|c|}
\hline & HB & Count & Mean & Median & Min & Max & $\begin{array}{l}\text { Standard } \\
\text { Deviation }\end{array}$ \\
\hline \multirow{4}{*}{ Stage } & I & 16 & 10.61 & 10.20 & 9.20 & 13.20 & 1.16 \\
\cline { 2 - 8 } & II & 30 & 9.70 & 9.60 & 8.80 & 10.80 & .52 \\
\cline { 2 - 7 } & III & 40 & 8.14 & 8.50 & 5.20 & 9.80 & 1.25 \\
\cline { 2 - 7 } & IV & 14 & 7.09 & 7.05 & 5.20 & 8.30 & 1.04 \\
\hline
\end{tabular}

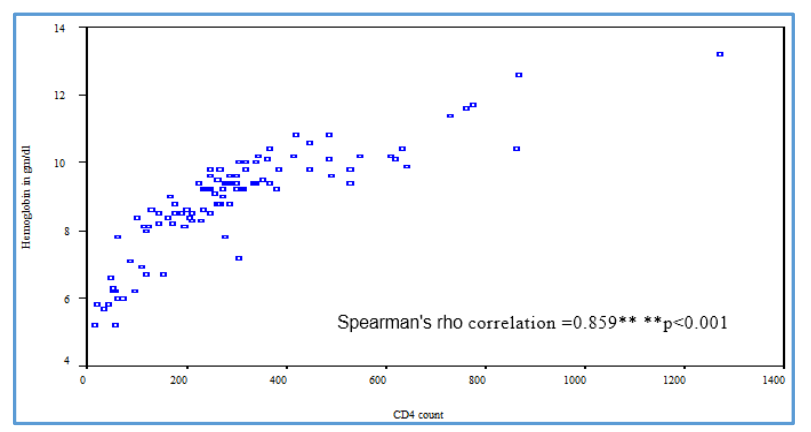

Figure 2. Distribution of HB in Relation to CD4 Count

\begin{tabular}{|c|c|c|c|c|c|c|c|}
\hline \multicolumn{2}{|c|}{} & Count & Mean & Median & Min & Max & $\begin{array}{c}\text { Standard } \\
\text { Deviation }\end{array}$ \\
\hline \multirow{3}{*}{ Stage } & I & 16 & 22.69 & 22.40 & 21.80 & 24.70 & .93 \\
\cline { 2 - 8 } & II & 30 & 20.16 & 20.10 & 19.20 & 22.10 & .61 \\
\cline { 2 - 7 } & III & 40 & 18.91 & 18.70 & 17.30 & 22.20 & .94 \\
\cline { 2 - 7 } & IV & 14 & 17.97 & 18.00 & 17.20 & 18.50 & .35 \\
\hline \multicolumn{8}{|c|}{ Table 4. Distribution of BMI $\mathbf{m} / \mathbf{k g}^{2}$} \\
\hline
\end{tabular}

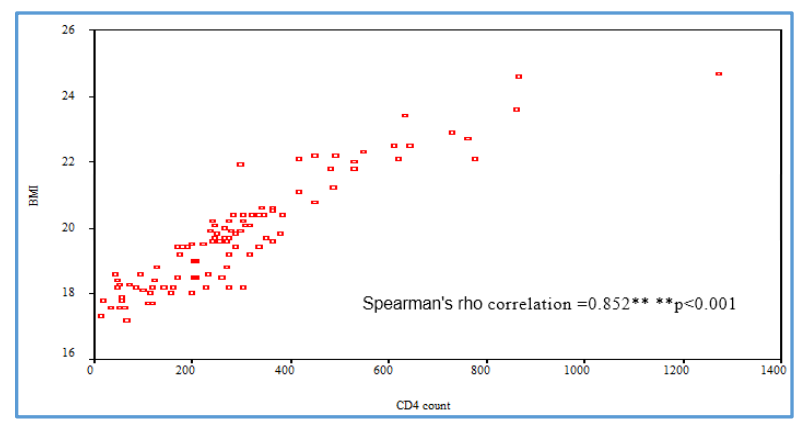

Figure 3. Distribution of BMI in relation to CD4 Count

\begin{tabular}{|c|c|c|c|c|c|c|c|}
\hline \multicolumn{2}{|c|}{} & Count & Mean & Median & Min & Max & $\begin{array}{c}\text { Standard } \\
\text { Deviation }\end{array}$ \\
\hline \multirow{4}{*}{ Stage } & I & 16 & 4.47 & 4.35 & 3.80 & 5.40 & .50 \\
\cline { 2 - 8 } & II & 30 & 3.77 & 3.75 & 3.20 & 4.20 & .28 \\
\cline { 2 - 7 } & III & 40 & 3.54 & 3.45 & 2.60 & 4.50 & .57 \\
\cline { 2 - 7 } & IV & 14 & 3.26 & 3.20 & 2.50 & 3.80 & .39 \\
\hline \multicolumn{8}{|c|}{ Table 5. Distribution of Serum } \\
Albumin gm/dL \\
\hline
\end{tabular}

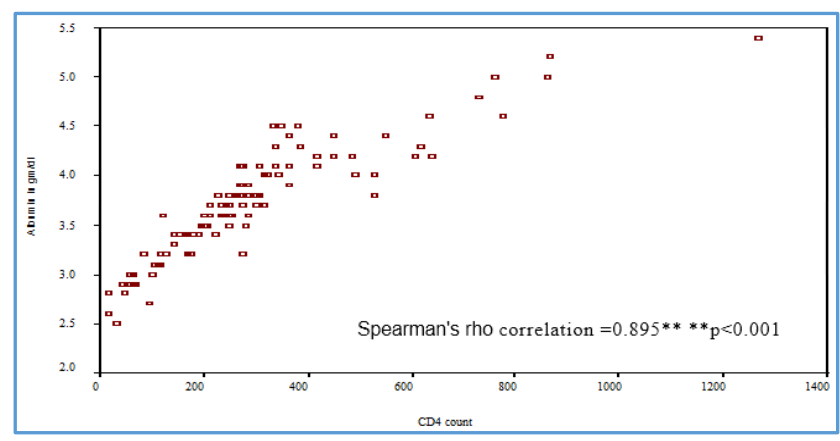

Figure 4. S. Albumin in relation to CD4 Count

\section{DISCUSSION}

One hundred patients with HIV infection were included in the study, in accordance to the inclusion/ exclusion criteria mentioned previously; 58 of them were males, 38 were females and 4 were transgenders; $51 \%$ of the study population was in their fourth decade. Although a majority (66\%) had completed secondary schooling, only $4 \%$ are degree/ diploma holders; $10 \%$ of the study population was non-literate. A majority (49\%) of the study population are labourers and self-employed, $26 \%$ of them are dependent on others for living which included housewives (16\%).

The range of CD4 counts in our study population was between 33 and 1270. Patients in the stage I HIV disease had a mean CD4 count of 665 [SD 219.82]. There was a significant drop in stage II to 298 [SD 74.54]. Stage III and IV had mean CD4 values of 195 [SD 118.03] and 146 [SD 85.09], respectively. Thus, there is a declining trend in the CD4 count with the progression of the disease. ${ }^{3}$

Evidence for the predictive value of TLC level is encouraging with several large studies ${ }^{4,5,6}$ confirming the significant association between a TLC of $<1200$ cells $/ \mathrm{mm} 3$ and subsequent disease progression or mortality. While TLC measurement has been validated ${ }^{7,8,9,10,11}$ as a means of monitoring disease progression in ART-naïve patients, its use for therapeutic monitoring is questionable. ${ }^{5}$

Thus, keeping TLC as the main surrogate marker, monitoring Haemoglobin, Body Mass Index and Serum albumin levels will provide us a sensitive low cost prediction of the CD4 count along with the progression of the disease in HIV/AIDS.

\section{CONCLUSION}

1. TLC is a sensitive surrogate marker for CD4 count in predicting the progression of HIV disease. TLC value of $<1550$ and $<2200$ corresponds to CD4 counts of $<200$ and $<350$, respectively.

2. HB levels correlated significantly with CD4 counts. Values of $<8.5 \mathrm{gm} \%$ and $<9.5 \mathrm{gm} \%$ predicted CD4 counts of $<200$ and $<350$, respectively. 
3. BMI too correlated significantly with CD4 counts. Values of $<18.5$ and $<19.5$ increased the sensitivity of TLC in predicting CD 4 counts of $<200$ and $<350$, respectively.

4. Serum Albumin levels correlated well with CD4 counts with values $<3.8 \mathrm{gm} \%$ and $<3.3 \mathrm{gm} \%$ predicting $\mathrm{CD} 4$ counts of 200 and 350 , respectively.

\section{REFERENCES}

[1] Castetbon K, Anglaret X, Toure S, et al. Prognostic value of cross-sectional anthropometric indices on short-term risk of mortality in human immunodeficiency virus-infected adults in Abidjan, Cote d'Ivoire. American Journal of Epidemiology 2001;154(1):75-84.

[2] Beck EJ, Kupek EJ, Gompels MM, et al. Correlation between total and CD4 lymphocyte counts in HIV infection: not making the good an enemy of the not so perfect. Int J STD AIDS 1996;7(6):422-8.

[3] Blatt SP, Lucey CR, ButzinCA, et al. Total lymphocyte count as a predictor of absolute CD4+ count and CD4+ percentage in HIV infected persons. JAMA 1993;269(5):622-6.

[4] Badri M, Wood R. Usefulness of total lymphocyte count in monitoring highly active antiretroviral therapy in resource-limited settings. AIDS 2003;17(4):541-5.

[5] Bhatia R, Narain JP. Guidelines for HIV diagnosis and monitoring of antiretroviral therapy - South East Asia Regional Branch. World Health Organisation Publications 2005.
[6] Blatt SP, Hendrix CW, Butzin CA, et al. Delayed-type hypersensitivity skin testing predicts progression to AIDS in HIV-infected patients. Annals of Internal Medicine 1993;119(3):177-84.

[7] Akinola NO, Olasode O, Adediran LA, et al. The search for a predictor of CD4 cell count continues: total lymphocyte count is not a substitute for CD4 cell count in the management of HIV-infected individuals in a resource-limited setting. Clin Infect Dis 2004;39(4):579-81.

[8] Anastos K, Shi Q, French AL, et al. Total lymphocyte count, hemoglobin and delayed-type hypersensitivity as predictors of death and AIDS illness in HIV-1infected women receiving highly active antiretroviral therapy. J Acquir Immune Defic Syndr 2004;35(4):383-92.

[9] Mahajan AP, Hogan JW, Snyder B, et al. Changes in total lymphocyte count as a surrogate for changes in CD4 count following initiation of HAART: implications for monitoring in resource-limited settings. J Acquir Immune Defic Syndr 2004;36(1):567-75.

[10] Annual Report on HIV/AIDS. Ministry of Health and Family welfare, Govt of India. 2009-2010.

[11] Balakrishnan P, Solomon S, Kumarasamy N, et al. Lowcost monitoring of HIV infected individuals on highly active antiretroviral therapy (HAART) in developing countries. The Indian Journal of Medical Research 2005;121(4):345-55. 